\title{
Bioactive Compounds from Aspergillus Terreus MP15, an Endophytic Fungus Isolated from Swietenia Macrophylla Leaf
}

\section{Olivia Chan Jade Yin*, Darah Ibrahim, Chong Chai Lee}

Industrial Biotechnology Research Laboratory, School of Biological Sciences, Universiti Sains Malaysia, 11800 Minden, Penang, MALAYSIA

Email for Correspondence: oliviacjy@yahoo.com

\begin{abstract}
Endophytes are important sources for the discovery of bioactive compounds. They are known as potential producers of novel compounds with antimicrobial activity. In this study, it aimed to study the bioactive metabolites present in the ethyl acetate extract from the endophytic fungus Aspergillus terreus MP15 of Swietenia macrophylla leaf. The ethyl acetate extract showed promising antibacterial activity against Gram-positive foodborne bacteria (Bacillus cereus, Bacillus spizizenii, Bacillus subtilis and Staphylococcus aureus) in disc diffusion assay. The extract was then subjected to thin layer chromatography (TLC) using dichloromethane: methanol (9:1) as a mobile solvent system and eleven spots with diverse polarities were obtained. The TLC chromatogram with bioactive spot was localized with bioautography assay and the result showed that the yellow spot with $R f$ value of 0.523 exhibited promising antibacterial activity against the four Gram-positive bacteria tested. Upon partial purification of the yellow bioactive fraction using column chromatography, the fraction 2a exhibited promising antibacterial activity. The GC-MS analysis of the yellow fraction 2a resulted in the detection of a major compound, di-n-octyl phthalate with $80 \%$ matching factor. Therefore, this compound may largely contribute to the antibacterial activity of the fraction and has potential to be food preservative and as a colorant. These results indicate that endophytic fungi isolated from medicinal plants could be a potential source for bioactive compounds.
\end{abstract}

Keywords: Endophytes, Aspergillus terreus, Yellow fraction, Antibacterial, Foodborne microorganisms, Swietenia macro-phylla plant, di-n-octyl phthalate

\section{INTRODUCTION}

Foodborne diseases or illnesses are emerging and continue to be a public health issue in the world today. Despite initiatives being done to prevent foodborne diseases, there are major outbreaks and cases reported from time to time. Moreover, many cases of foodborne diseases are left unreported, especially in developing countries (Newell et al., 2010). Besides that, diarrheal diseases alone kill 1.5 million children annually worldwide (Hanson et al., 2012). On the other hand, the emergence of antimicrobial resistance microorganisms is further complicating the eradication of foodborne diseases (Newell et al., 2010). The explanation for this is the ability of microorganisms to acquire resistance against antimicrobial substances such as the emergence of ciprofloxacin resistance Campylobacter (Agunos et al., 2013). Therefore, new natural sources of antibiotics to treat foodborne pathogens are seriously needed. In addition to that, medicinal plants have been recognized as potential sources of endophytic fungi having antimicrobial properties (Garcia et al., 2012).

Swietenia macrophylla King (Meliaceae) is a tropical plant with significant medicinal value and has been reported to contain various chemical compounds with pharmacological activities (Ahmad et al., 2013). It was reported to exhibit antimicrobial, anti-inflammatory, antioxidant, anti-diarrheal, anticancer and anti-diabetic activities (Tan et al., 2009; 
Moumita et al., 2011; Soheil et al., 2013). Furthermore, the endophytic fungi residing in the plants reported being potential producers of pharmaceutical products. Darah et al. (2014) found that $68.3 \%$ of endophytic fungi from $S$. macrophylla leaves exhibited antimicrobial activity towards most of the tested microorganisms. Endophytic fungi are the microorganisms that grow inside the plants and are relatively unexplored producers of metabolites useful to pharmaceutical and medicinal industries (Petrini et al., 1992; Ramasamy et al., 2010). Furthermore, fungal endophytes residing within these plants could also produce metabolites similar to or with more pronounced activity than that of their respective hosts (Strobel, 2002). Therefore, in this study, the ethyl acetate extract and its fractions especially the yellow fraction of A. terreus MP15 isolated from the leaf of S. macrophylla (Darah et al., 2014), was studied for its antibacterial activity and to determine the possible antibacterial bioactive compound(s) involved in it.

\section{Materials AND Methods}

\section{Maintenance of Aspergillus terreus MP15}

An endophytic fungal isolate A. terreus MP15 that was deposited in Industrial Biotechnology Research Laboratory, Universiti Sains Malaysia, Penang, Malaysia was used in this study. The fungus was one of the endophytes that previously isolated from a healthy old leaf of S. macrophylla King (Darah et al., 2014). It was cultivated on malt extract agar (MEA; Merck, Germany) supplemented with host plant extract (Tong et al., 2012; Darah et al., 2014) and stored as $20 \%$ glycerol stock at $-20^{\circ} \mathrm{C}$. The stock was subcultured on fresh medium every month to ensure its viability.

\section{Test microorganisms}

The foodborne test microorganisms used were provided by Industrial Biotechnology Research Laboratory (IBRL), Universiti Sains Malaysia, Penang. Four Gram-positive (B. cereus, B. spizizenii, B. subtilis and S. aureus) and three Gram-negative (Klebsiella pneumoniae, Yersinia enterocolitica and Proteus mirabilis) bacteria were used as test microorganisms and subcultured every two weeks on fresh nutrient agar slant (Oxoid, England).

\section{Fungal cultivation and extraction of metabolites}

The cultivation medium was prepared by introducing two actively growing pure mycelial agar plugs $(10 \mathrm{~mm}$ in diameter $\times 4 \mathrm{~mm}$ thickness and were excised from the periphery of 7 days old fungal culture) into $250 \mathrm{~mL}$ Erlenmeyer flask containing $100 \mathrm{~mL}$ yeast extract sucrose (YES; which consisted yeast extract, $20 \mathrm{~g} / \mathrm{L}$; sucrose, $40 \mathrm{~g} / \mathrm{L} ; \mathrm{MgSO}_{4}, 0.5 \mathrm{~g} / \mathrm{L}$ ) broth amended with host plant water extract (Tong et al., 2011). The host plant water extract was prepared by boiling $5 \mathrm{~g}$ powdered plant material in $1000 \mathrm{~mL}$ distilled water for $30 \mathrm{~min}$ and filtered with Whatman No.1 filter paper. Subsequently, the cultures were cultivated at $25^{\circ} \mathrm{C}$ under a dark condition for 14 days prior to the separation via filtration of fermented broth and fungal biomass using sterile Whatman No. 1 filter paper. Following that, the fungal biomass was freeze-dried, ground into powder form and later macerated in methanol $(1: 50, \mathrm{w} / \mathrm{v})$ for overnight at room temperature. After maceration, the mixture was filtered using Whatman No. 1 filter paper. The filtrate, which was the methanolic extract was then concentrated to dryness by a rotary evaporator and dried in a fume hood until dried crude paste formed. The filtered broth was extracted thrice with an equal volume of ethyl acetate $(1: 1, \mathrm{v} / \mathrm{v})$ and shaken vigorously for 10 min using liquidliquid partitioning method. The upper organic phase was concentrated under reduced pressure using a rotary evaporator and also dried in a fume hood until dried crude paste formed.

\section{Disc diffusion susceptibility test}

The assay was performed according to Tong et al. (2011) with slight modifications. The inocula were prepared by transferring a few single colonies of fresh bacterial culture into five $\mathrm{mL}$ of sterile distilled water and mixing well to obtain cell suspensions. Subsequently, the inocula of each test bacteria (approximately $1 \times 10^{8} \mathrm{CFU} / \mathrm{mL}$ ) were prepared by comparing them to $0.5 \mathrm{McF}$ arland standards. The test bacterial inocula were then seeded on Mueller Hinton Agar (MHA) (Hi-media, India) using a swab streaking method. Fungal extract with a concentration of 50 $\mathrm{mg} / \mathrm{mL}$ was prepared by dissolving $50 \mathrm{mg}$ of extract in $0.2 \mathrm{~mL}$ dimethyl sulfoxide (DMSO), subsequently added with $0.8 \mathrm{~mL}$ sterile distilled water. Twenty microliters of extract was then pipette onto $6 \mathrm{~mm}$ sterile Whatman antibiotic disc and placed on the surface of the MHA medium seeded with test microorganisms. One percent DMSO was applied as a negative control whereas $30 \mu \mathrm{g} / \mathrm{mL}$ chloramphenicol was used as a positive control. The plates were incubated at $37^{\circ} \mathrm{C}$ for $24 \mathrm{hrs}$. Subsequently, the diameters of zones of inhibition were measured in millimeter. The experiments were done in triplicates for three separate occasions.

\section{Thin layer chromatography}

Thin layer chromatography (TLC) was performed according to protocols mentioned by Atalla et al. (2008) with slight modifications. An aluminium sheet with pre-coated silica gel $60 \mathrm{~F}_{254}$ (Merck, Germany) was measured and subsequently cut $(1 \mathrm{~cm}$ width $\times 10 \mathrm{~cm}$ length). Following that, the ethyl acetate extract was then spotted at $1 \mathrm{~cm}$ from the bottom of the TLC plate. Subsequently, the TLC plate was then put in a glass jar previously saturated with 
solvent system dichloromethane: methanol $(9: 1)(v / v)$. The glass jar was covered tightly. The solvent system was left to rise on the TLC plate until it reached the solvent front. The solvent front was then marked with a pencil. Following that, for the detection of bioactive compounds, the developed chromatogram was examined visually and also observed under short $(254 \mathrm{~nm})$ and long $(366 \mathrm{~nm})$ wavelength ultraviolet light. Besides that, it was exposed to iodine vapour in a closed jar containing iodine crystals. The $\mathrm{R} f$ values of the separated spots were determined subsequently.

\section{Contact bioautography}

Contact bioautography was done according to the protocols explained by Choma and Grzelak (2010) with slight modifications. The inoculums of test bacteria were prepared (approximately $1 \times 10^{8} \mathrm{CFU} / \mathrm{mL}$ ) and inoculated on the agar media, respectively. The developed TLC plate was then placed on the agar previously seeded with test bacteria for overnight to allow diffusion of bioactive compounds. Following that, the TLC plate was removed, and the agar layer was incubated at $37^{\circ} \mathrm{C}$ for overnight. The zone of inhibition was then observed on the agar plate. The spots that exhibited antibacterial activity were located by comparing to the TLC plate previously removed.

\section{Column chromatography}

The fungal extract was subjected to fractionation using silica gel column chromatography $(0.030-0.200 \mathrm{~mm}, 60 \mathrm{~A})$ (Acros Organics, US) with $2 \mathrm{~cm}$ in diameter and $45 \mathrm{~cm}$ in height, as a stationary phase according to the protocols reported by Ezhil et al. (2014) with slight modifications. About 35 to $40 \mathrm{~g}$ of silica gel was dissolved using solvent system dichloromethane: methanol $(9: 1, v / v)$ as a movable phase and mixed into slurry. The slurry was then poured into the column and left for overnight. On the following day, the fungal extract was dissolved in few drops of solvent system, dichloromethane: methanol at ratio 9:1 $(v / v)$ and transferred into the column using a clean Pasteur pipette. The column was then left to develop and following that fresh solvent was loaded in the column from time to time to prevent dry-off of the mobile phase. The bioactive fraction was collected and the compounds present were checked with TLC.

\section{Broth microdilution assay}

The minimum inhibitory concentration (MIC) of yellow fraction collected from column chromatography was determined regarding to the protocols reported by Jorgensen and Ferraro (2009). This assay was done in 96 wells microtitre plates (HmbG, USA). The fungal extract was two-fold diluted with sterile Muller Hinton broth (MHB) (Himedia, India). Subsequently, $100 \mu \mathrm{L}$ of the extract was pipette into each well of the 96 -wells plate. Meanwhile, the bacterial inoculum $\left(2 \times 10^{7} \mathrm{CFU} / \mathrm{mL}\right)$ was prepared and then five $\mu \mathrm{L}$ of the bacterial suspension was dispensed into the wells. Finally, $95 \mu \mathrm{L}$ of MHB was added into the well to give a final volume of $200 \mu \mathrm{L}$ and the final concentration of bacteria was $5 \times 10^{5} \mathrm{CFU} / \mathrm{mL}$. On the other hand, sterility control consisted of $200 \mu \mathrm{L}$ MHB broth, whereas, for growth control, the fungal extract was substituted with $1 \%$ DMSO. Subsequently, the plate was incubated overnight at $37^{\circ} \mathrm{C}$. On the following day, $40 \mu \mathrm{L}$ of $0.2 \mathrm{mg} / \mathrm{mL}$ p-iodonitrotetrazolium violet salt (INT) (Sigma, USA) dissolved in ethanol was dispensed in each well to examine the microbial growth. The MIC was recorded as the lowest concentration of extract used to inhibit the growth of test pathogens. Besides that, the viable cells were enumerated with serial dilutions and plating on NA (Oxoid, England) to determine the MBC. The MBC was recorded as the lowest concentration of extract which caused $99.9 \%$ reduction in growth compared to the control.

\section{Gas chromatography-mass spectrometry (GC-MS) analysis}

The bioactive fraction was subjected to Hewlett-Packed 6890N Network gas chromatography system equipped with Hewlett-Packard 5973 inert mass selective detector mass spectrophotometer to detect the possible chemical compounds present. The column used was HP-5MS (Agilent, USA). The cycle was as follows: oven temperature at 70 ${ }^{\circ} \mathrm{C}$ for $2 \mathrm{~min}$; rose to $250{ }^{\circ} \mathrm{C}$ for $30 \mathrm{~min}$ and held at $250{ }^{\circ} \mathrm{C}$ for $20 \mathrm{~min}$. Subsequently, the carrier helium gas was supplied in a constant rate at $1.2 \mathrm{~mL} / \mathrm{min}$. The separated chemical compounds from the extract were identified by comparing to the NISTO2 library by computer matching.

\section{RESULTS}

\section{Antibacterial activity}

Antibacterial activity of the crude ethyl acetate and methanolic extracts of A. terreus MP15 isolated from $S$. macrophylla leaf are shown in Table 1. The results showed that the ethyl acetate extract that contained the compounds secreted extracellularly into the cultivation medium by the fungal isolate only inhibited the growth of four Grampositive bacteria tested (B. cereus, B. spizizenii, B. subtilis and S. aureus). The diameter of zones of inhibition produced by the extract from the cultivation medium without the addition of host plant extract against B. cereus, B. spizizenii, $B$. subtilis and $S$. aureus were $13.3 \pm 0.1,13.7 \pm 0.6,12.7 \pm 0.6$ and $13.0 \pm 1.0 \mathrm{~mm}$, respectively; compared to the one with the addition of host plant extract with diameter $10.3 \pm 0.4,13.3 \pm 0.6,11.3 \pm 0.6$ and $12.7 \pm 1.2 \mathrm{~mm}$, respectively. 
Furthermore, there were no inhibition zones produced by the methanolic extract against the four test bacteria, indicating that the biomass (intracellular) did not possess antibacterial compounds. The results also revealed that Gram-negative bacteria were resistant to both of the extracts.

Table 1: Antibacterial activity of the crude ethyl acetate and methanolic extracts of Aspergillus terreus MP15 isolated from Swietenia macrophylla leaf

\begin{tabular}{|c|c|c|c|c|}
\hline \multirow{3}{*}{ Test bacteria } & \multicolumn{4}{|c|}{ Diameter of zone of inhibition $(\mathrm{mm})^{*}$} \\
\hline & \multicolumn{2}{|c|}{ Ethyl acetate extract } & \multicolumn{2}{|c|}{ Methanol extract } \\
\hline & Without Plant Extracts & With Plant Extracts & Without Plant Extracts & With Plant Extracts \\
\hline \multicolumn{5}{|c|}{ Gram-positive bacteria } \\
\hline Bacillus cereus & $13.3 \pm 0.1$ & $10.3 \pm 0.4$ & - & - \\
\hline Bacillus spizizenii & $13.7 \pm 0.6$ & $13.3 \pm 0.6$ & - & - \\
\hline Bacillus subtilis & $12.7 \pm 0.6$ & $11.3 \pm 0.6$ & - & - \\
\hline Staphylococcus aureus & $13.0 \pm 1.0$ & $12.7 \pm 1.2$ & - & - \\
\hline \multicolumn{5}{|c|}{ Gram-negative bacteria } \\
\hline Klebsiella pneumoniae & - & - & - & - \\
\hline Proteus mirabilis & - & - & - & - \\
\hline Yersinia enterocolitica & - & - & - & - \\
\hline
\end{tabular}

*Values are means of three replicates \pm standard deviation; DMSO was used as negative control; Chloramphenicol was used as positive control; diameter of disc: $6.0 \mathrm{~mm}$.

\section{Thin layer chromatography}

Thin layer chromatography (TLC) is the easiest method to separate the components in the ethyl acetate extract. In this study, the solvent system optimized was dichloromethane: methanol at ratio 9:1. It is able to separate the crude extract into 11 spots with broad range of polarities (Figure 1). Table 2 summarizes the $R f$ values and the colour description of the 11 separated spots obtained from the TLC visualized under visible light, short and long wavelengths, as well as after sprayed with iodine vapour. Among the spots, only two were visible yellow spot, seven spots were viewed under exposure to short wavelength $(254 \mathrm{~nm})$ and all the spots separated florescent under long wavelength $(366 \mathrm{~nm})$. Following that, the spot that exhibited antimicrobial activity was detected with bioautography assay.

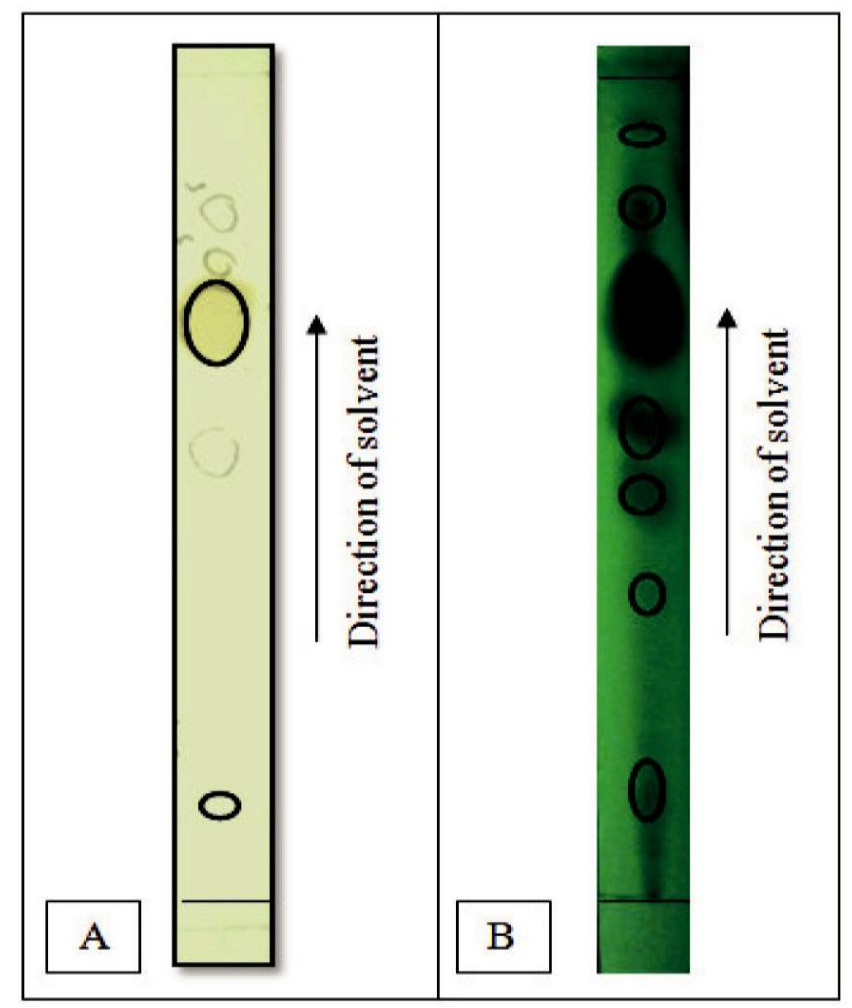

Figure 1: TLC chromatograms of fungal isolate $A$. terreus MP15 crude ethyl acetate extract viewed under (A) visible light and (B) short wavelength with solvent system dichloromethane: methanol at ratio 9:1 
Table 2: Colour descriptions and $R f$ values of the separated spots on TLC under visible light, short and long wavelengths and after iodine vapour spray

\begin{tabular}{|c|c|c|c|c|c|}
\hline Spots & Short Wavelength & Long wavelength & Visible Light & Iodine Spray & R $f$ values \\
\hline 1 & Dark spot & Blue & Yellow & - & 0.060 \\
\hline 2 & - & Yellow & - & - & 0.116 \\
\hline 3 & - & Yellow & - & - & 0.174 \\
\hline 4 & Dark spot & Yellow & - & - & 0.233 \\
\hline 5 & Dark spot & Blue & - & - & 0.291 \\
\hline 6 & - & Blue & - & - & 0.349 \\
\hline 7 & Dark spot & Yellow & - & - & 0.407 \\
\hline 8 & - & Blue & - & - & 0.453 \\
\hline 9 & Dark spot & Violet & Yellow & Brown & 0.523 \\
\hline 10 & Dark spot & Fluorescence Blue & - & - & 0.616 \\
\hline 11 & Dark spot & Blue & - & - & 0.919 \\
\hline
\end{tabular}

\section{Bioautography assay}

After procurement of separated spots on a thin layer chromatogram, the bioactive spots were localized with bioautography assay. The results of the bioautography assay are shown in Table 3 . The yellow coloured visible spot was detected to exhibit antibacterial activity against all the tested Gram-positive bacteria (B. cereus, B. subtilis, B. spizizenii and $S$. aureus). This yellow coloured bioactive fraction was then targeted and collected in column chromatography for further examinations.

Table 3: Bioautography results of $A$. terreus MP15 fungal ethyl acetate extract and the R $f$ values of bioactive spots

\begin{tabular}{|c|c|c|c|c|c|}
\hline \multirow{2}{*}{ Spots } & \multirow{2}{*}{ Rf values } & \multicolumn{5}{|c|}{ Diameter of zone of inhibition (mm) } \\
\cline { 3 - 6 } & & B. cereus & B. spizizenii & B. subtilis & S. aureus \\
\hline 1 & 0.060 & - & - & - & - \\
\hline 2 & 0.116 & - & - & - & - \\
\hline 3 & 0.174 & - & - & - & - \\
\hline 4 & 0.233 & - & - & - & - \\
\hline 5 & 0.291 & - & - & - & - \\
\hline 6 & 0.349 & - & - & - & - \\
\hline 7 & 0.407 & - & - & - & - \\
\hline 8 & 0.453 & - & - & - & - \\
\hline 9 & 0.523 & $* 5.0 \pm 0.0$ & $5.0 \pm 0.0$ & $5.0 \pm 0.0$ & $10.0 \pm 0.0$ \\
\hline 10 & 0.616 & - & - & - & - \\
\hline 11 & 0.919 & - & - & - & - \\
\hline
\end{tabular}

\section{Column chromatography}

Upon the detection of bioactive spot that contributed to the antibacterial activity of the crude extract, column chromatography was done to procure the partial purified bioactive yellow fraction. Following that, the bioactive yellow fraction was subjected to thin layer chromatography for checking of the fractions present. Table 4 shows the four sub-fractions that were collected from the separation using column chromatography. Among the spots, yellow coloured spot (2a) with the $R f$ value 0.690 was the most active spot in the bioautography assay. Therefore, the targeted bioactive fraction was further collected and subjected to further tests.

Table 4: $R f$ values and colour of the spots on TLC chromatogram for yellow fraction using solvent system dichloromethane: methanol at ratio 9:1

\begin{tabular}{|c|c|c|c|c|}
\hline Sub-fraction on TLC & Under visible light & Under short wavelength & Under long wavelength & $\mathrm{R} f$ value \\
\hline $1 \mathrm{a}$ & Colourless & - & Blue & 0.536 \\
\hline $2 \mathrm{a}^{*}$ & Yellow & Dark spot & Violet & 0.690 \\
\hline $3 \mathrm{a}$ & Colourless & Dark spot & Fluorescence blue & 0.774 \\
\hline $4 \mathrm{a}$ & Colourless & Blue & Colourless & 0.833 \\
\hline
\end{tabular}

\section{Broth microdilution assay}

The collected yellow bioactive fraction (2a) was then tested for its MIC and MBC values. Table 5 shows the results of 
MIC, MBC and the ratio of MBC/MIC. The MIC values for S. aureus and B. spizizenii were $500 \mu \mathrm{g} / \mathrm{mL}$ while for $B$. subtilis and B. cereus were $250 \mu \mathrm{g} / \mathrm{mL}$. On the other hand, the MBC values were $500 \mu \mathrm{g} / \mathrm{mL}$ for S. aureus, B. spizizenii and B. subtilis. The MBC/MIC ratio for S. aureus, B. cereus and B. spizizenii were one but two for B. subtilis.

Table 5: MIC and MBC values of yellow fraction of $A$. terreus MP15 ethyl acetate extract

\begin{tabular}{|l|c|c|c|}
\hline \multirow{2}{*}{ Test bacteria } & \multicolumn{3}{|c|}{ Yellow Fraction } \\
\cline { 2 - 4 } & MIC value (mg/mL) & MBC value (mg/mL) & MBC/MIC ratio \\
\hline Gram positive & & & 1 \\
\hline S. aureus & 0.50 & 0.50 & 1 \\
\hline B. cereus & 0.25 & 0.25 & 1 \\
\hline B. spizizenii & 0.50 & 0.50 & 2 \\
\hline B. subtilis & 0.25 & 0.50 & \\
\hline
\end{tabular}

Bioactive fraction which contributed to the antibacterial activity of extract

\section{Gas chromatography-mass spectrometry analysis}

GC-MS analysis was done to identify the possible compounds in the bioactive fraction of A. terreus MP15 extract. Figure 2 shows the GC-MS chromatogram of the yellow fraction 2a. In addition to that, a total of 11 peaks were observed on the chromatogram. Besides that, Table 6 shows the number of peaks and the retention time, area and matching factor of the compounds present. Two compounds showed matching factor of more than $80 \%$. Among the possible compounds identified, eight major groups of compounds detected were amine, aromatic ketones, carboxylic acid ester, coumarin derivatives, dicarboxylic acid, heterocyclic compounds, hydrazide derivatives and imine. Several of the compounds were known to exhibit antibacterial, antioxidants and other biological activities. Hence, they may be contributing to the antibacterial and antioxidant activities of A. terreus MP15 bioactive fraction. Figure 2 shows the major compound of the yellow bioactive fraction was at the peak 10 with area of $51.12 \%$ and retention time $13.05 \mathrm{~min}$. It was identified as di-n-octyl phthalate with matching factor $80 \%$.

Table 6: Characteristics of the chemical compounds from GCMS analysis of the yellow fraction of A. terreus MP15 ethyl acetate extract. A total of 11 compounds were detected

\begin{tabular}{|c|c|c|c|c|c|}
\hline No & Compound & $\begin{array}{l}\text { Retention } \\
\text { time (min) }\end{array}$ & Area (\%) & $\begin{array}{l}\text { Matching } \\
\text { factor (\%) }\end{array}$ & Structure \\
\hline 1 & $\begin{array}{l}\text { 4-methoxy-2- } \\
\text { Benzothiazolamine }\end{array}$ & 9.33 & 0.47 & 49 & \\
\hline 2 & $\begin{array}{l}\text { 2,5-Dihydroxy } \\
\text { propiophenone }\end{array}$ & 9.49 & 6.87 & 64 & \\
\hline 3 & 6-chloro- quinazoline & 9.60 & 1.49 & 30 & \\
\hline 4 & $\begin{array}{l}\text { p-(Dimethylamino) } \\
\text { benzaldehyde oxime }\end{array}$ & 9.67 & 4.16 & 47 & \\
\hline
\end{tabular}




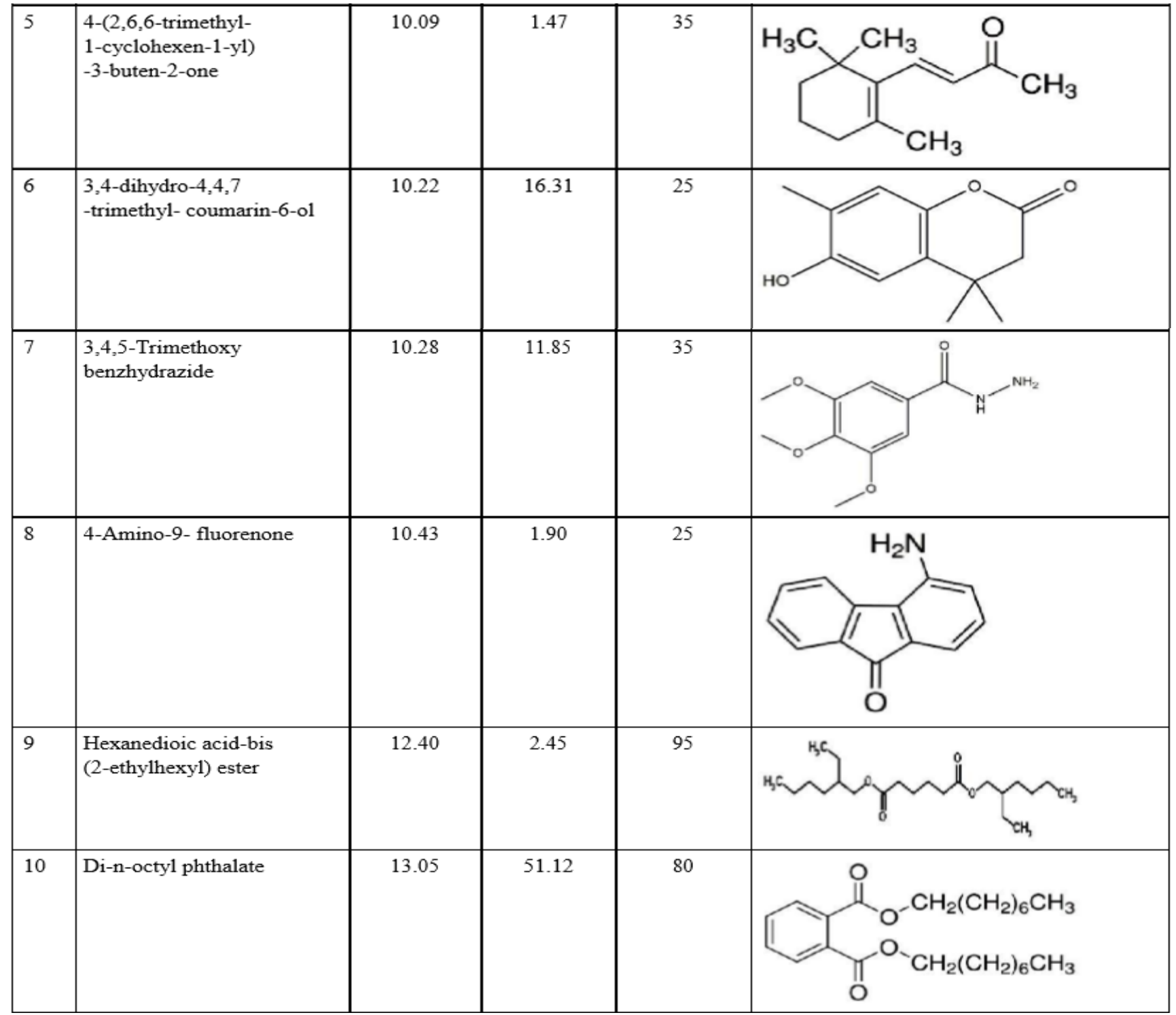

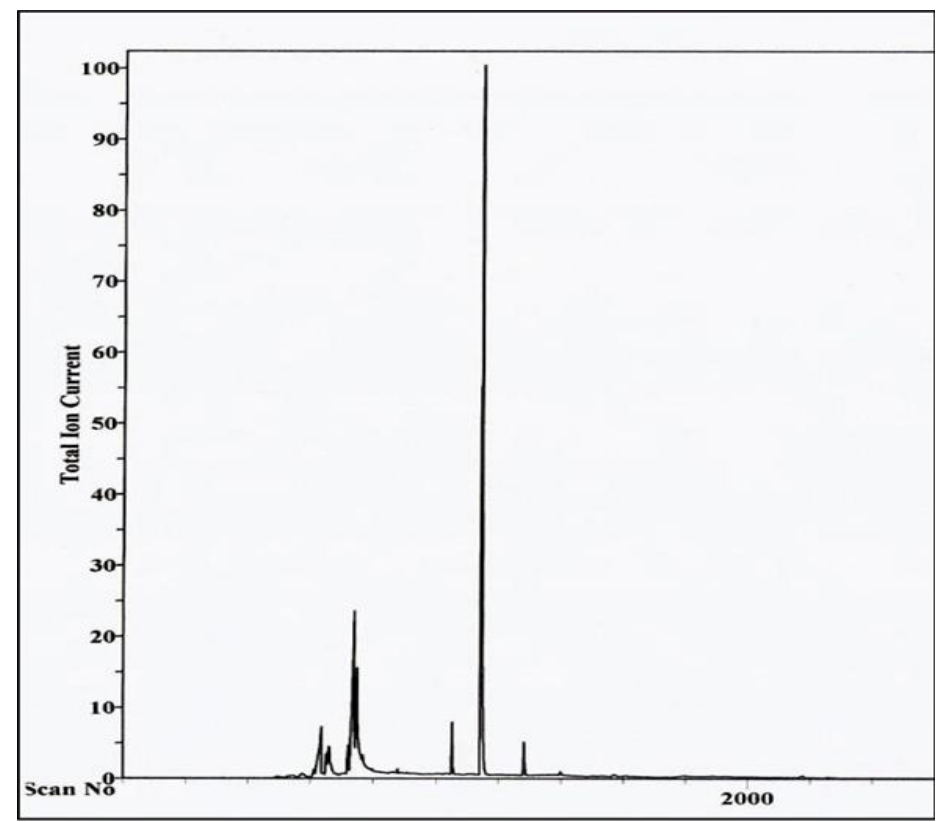

Figure 2: The GCMS chromatogram of A. terreus MP15 fungal ethyl acetate extract 


\section{Discussion}

Endophytic fungi are relatively unexplored fungal species that are now considered as exciting novel sources for obtaining new bioactive compounds useful to pharmaceutical and agricultural industries (Petrini et al., 1992; PorrasAlfaro and Bayman, 2011). They are the microorganisms that grow inside the plants that allow both (plant and endophytes) to be beneficial. Besides residing asymptomatically inside the living plant tissues, endophytes could also produce metabolites similar to or with more activity than that of their respective hosts (Strobel, 2002) and it was confirmed when taxol was obtained from an endophytic fungi isolated from Taxus brevifolia (Strobel et al., 1996).

There are many reports about antimicrobial compounds produced by endophytes in cultures that were active against pathogenic microorganisms. Chareprasert et al. (2006) reported an antimicrobial activity exhibited by endophytic fungi isolated from teak and rain trees, whereas Sadrati et al. (2013) highlighted the antimicrobial activity from endophytes isolated from wheat. These fungi were found to produce some metabolites active against bacteria. Tong et al. (2012) and Tong et al. (2014) also found that Penicillium minioluteum ED24 and Phomopsis sp. ED2 isolated from Orthosiphon stamineus Benth produced extracellular antimicrobial compounds that were effective against Grampositive bacterial cells. In this study, the antibacterial activity of the ethyl acetate extract of the A. terreus MP15 also showed a significant effect on Gram-positive bacterial cells.

The results obtained from this study correlated with the findings of other reports (Ramasamy et al., 2010; Tong et al., 2014; Darah et al., 2014) and they reported the antimicrobial activity of endophytes. However, the reason for the different sensitivity between Gram-positive and Gram-negative bacteria could be ascribed to the morphological and structural differences between these microorganisms. Gram-negative bacteria have an outer polysaccharide membrane that carries the structural lipopolysaccharide components. It makes the cell wall impermeable to lipophilic solutes. In addition to that, it explains why the performance of the extract was poorer in the Gram-negative bacteria.

In the process of isolating and fractionating the ethyl acetate extract of $A$. terreus MP15, a bioassay-guided technique was used. Starting with thin layer chromatography (TLC) which is easy to carry out, cheap and effective (Kustrin and Hettiarachchi, 2014), 11 spots with a broad range of polarities were obtained. The optimized solvent system used was dichloromethane: methanol at the ratio of 9:1. Nagaraja et al. (2011) also used dichloromethane: ethyl acetate: methanol at ratio 8:1:1 as the solvent system and was able to separate the crude ethyl acetate extract of $A$. terreus st. 1 . into six spots. Therefore, the usage of a proper solvent system enables the separation of $A$. terreus MP15 crude ethyl acetate into spots with a wider range of polarity. Among the spots, only two were visible yellow spots, seven spots were viewed under exposure to $254 \mathrm{~nm}$ (short wavelength), and all the spots separated florescent under $366 \mathrm{~nm}$ (long wavelength). The fluorescence of the spots may due to the presence of phenolics compounds that can absorb ultraviolet light (Chandrakuntal et al., 2006). Following that, the spot that exhibited antimicrobial activity was detected with bioautography assay.

Bioautography assay is simple, cheap, and it allows target-directed isolation of bioactive constituents for further examination, hence preventing isolation of inactive compounds (Suleimana et al., 2010). The yellow coloured visible spot was detected to exhibit antibacterial activity against all the tested Gram-positive bacteria (B. cereus, B. subtilis, B. spizizenii and $S$. aureus). The yellow coloured bioactive fraction was then targeted and collected in column chromatography for further examinations. Four sub-fractions (1a, 2a, 3a and 4a) were collected and among the spots, yellow coloured spot $2 \mathrm{a}$ with the $\mathrm{R} f$ value 0.690 possessed the bioactive spot in bioautography assay.

The MIC values of the sub-fraction 2a for S. aureus and B. spizizenii were $500 \mu \mathrm{g} / \mathrm{mL}$ while for B. subtilis and B. cereus were $250 \mu \mathrm{g} / \mathrm{mL}$. According to Kuete (2010), the cut-off value for MIC is as follows: significant (MIC $\leq 100 \mu \mathrm{g} / \mathrm{mL})$, moderate $(100 \leq \mathrm{MIC} \leq 625 \mu \mathrm{g} / \mathrm{mL})$ or weak $(\mathrm{MIC}>625 \mu \mathrm{g} / \mathrm{mL})$. Therefore, the MIC values for the yellow fraction against the test microorganisms were in a moderate range of potency. Furthermore, the ratio of MBC to MIC for all the four test bacteria were less than 4 , and the results suggested that the yellow fraction was bactericidal against the bacteria. Pankey and Sabath (2004) stated that if the ratio was more than 4 , the extract was noted as bacteriostatic but if the extract was less than 4 , it was bactericidal. In addition to that, the yellow fraction can be a promising candidate for food preservative and also possible as a yellow food colorant.

In an attempt to identify the possible bioactive compound(s) of A. terreus MP15 extract that possessed antibacterial activity, GC-MS was applied. The number of peaks, the retention time, area and matching factor of the compounds present were compared with those of in the NIST database. Two compounds showed a matching factor of more than $80 \%$. Among the possible compounds identified, eight major groups of compounds detected were the amine, aromatic ketones, carboxylic acid ester, coumarin derivatives, dicarboxylic acid, heterocyclic compounds, hydrazide derivatives and imines. Furthermore, several compounds were reported in literature to exhibit antibacterial, antioxidants and other biological activities. Hence, they may be contributing to the antibacterial and antioxidant 
activities of $A$. terreus MP15 bioactive fraction. In addition to that, 2,5-dihydroxypropiophenone with matching factor 64\% was reported in Prasanna et al. (2012) as a phenolic compound that exhibit antibacterial, antioxidant, anticancer and antiviral activities. Besides that, another compound, 4-(2,6,6-trimethyl-1-cyclohexen-1-yl)-3-buten-2-one was also reported in Petrus et al. (2014) to contribute to the antioxidant activity. Furthermore, compound di-n-octyl phthalate identified with matching factor $80 \%$ was reported as one of the major compounds that exhibit antibacterial and antioxidant activities in a study done by Vimalavady and Kadavul (2013). In another study done by Tambekar et al. (2014), decanedioic acid-bis(2-ethylhexyl) ester identified was reported to exhibit strong antibacterial activity against test microorganisms. Therefore, those compounds may be the potential producers of antibacterial and antioxidant activities of the bioactive fraction of $A$. terreus MP15.

Moreover, based on the GC-MS chromatogram, the major compound of the yellow bioactive fraction was at the peak 10 with an area of $51.12 \%$ and retention time $13.05 \mathrm{~min}$. It was identified as di-n-octyl phthalate with matching factor $80 \%$. Based on TRC database, it is a pale yellow solid and utilised as addictives and plasticizers. Furthermore, they are also used in aromatics, pharmaceutical and as intermediates (Petersen and Jensen, 2010). In addition to that, it was reported to exert a wide range of biological activities such as antimicrobial, antifungal and antioxidant in a study done by Vimalavady and Kadavul (2013). Besides that, in a study done by Grover and Patni (2003), it was reported to exhibit antibacterial and antifouling activities. Furthermore, in another study done by Ashok and Jayaprakash (2012), it is the major compound that may responsible for the antimicrobial activity of the stem of Santalum album. Thus, di-n-octyl phthalate was identified as the major compound in the ethyl acetate extract of $A$. terreus MP15 and it may be the most potential compound that contributes to the antibacterial activities of the extract.

Report from this study supports the growing evidence that bioactive compounds produced by endophytic fungi may not only be involved in the host-endophyte relationship, but may also ultimately have applicability in other industries. Accordingly, because of their role in conferring plants the ability to adapt to stress conditions, and also proven or perceived sources of secondary metabolites with pharmaceutical importance, the study of fungal endophytes is expected to become an important component of fungal biology. Endophytic fungi can be exploited for the bioactive compound since many workers have demonstrated that the endophytes isolated from medicinal plants are excellent producers of strong fungicidal, bactericidal and cytotoxic metabolites (Wang et al., 2007). Endophytes are present in almost all plant species and have been recognized as a potential source of novel medicinal compounds. From this work, we can conclude that the endophytic fungi have a wide variety of bioactive compounds.

\section{CONCLUSION}

The potential pharmacological bioactive compounds from the endophytic fungus A. terreus MP15 extract exhibited promising antibacterial activity against several foodborne microorganisms. The yellow bioactive fraction procured showed that the di-n-octyl phthalate was the major compound with $80 \%$ and together with other several compounds may contribute to the antibacterial activity of the fraction.

\section{REFERENCES}

Agunos, A, Leger, D, Avery, BP, Parmley, EJ, Deckert, A, Carson, CA and Dutil, L. (2013). Ciprofloxacin-resistant Campylobacter spp. In retail chicken, West Canada. Emergence of Infectious Diseases, 19(7), 1121-1124.

Ahmad, MME, Nagib, AE, and Hesham, AE. (2013). A review on the phytopharmacological effect of Swietenia macrophylla. International Journal of Pharmacy and Pharmaceutical Sciences, 5(3), 47-53.

Ashok, K, and Jayaprakash, P. (2012) Screening of active phytocompounds by GCMS study and antimicrobial activity in the stem of Santalum album. International Journal of Current Pharmaceutical Research, 4(3), 43-44.

Atalla, M, Zeinab, HK, Eman, RH, Amani, AY, and Abeer, AA. (2008). Production of some biologically active secondary metabolites from marine-derived fungus, Varicosporina ramulosa. Malaysia Journal of Microbiology, 4(1), 14-24

Chandrakuntal, K, Thomas, NM, Kumar, PG, Lalorya, M and Laloray, MM. (2006) Fluorescence resonance energy transfer between polyphenolic compounds and riboflavin indicates a possible accessory photoreceptor function for some polyphenolic compounds. Photochemistry and Photobiology, 82(5), 1358-1364

Chareprasert S, Piapukiew J, Thienhirun S, Whalley A and Sihanonth P. (2006). Endophytic fungi of teak leaves Tectona grandis L. and rain tree leaves Samanea saman Merr. World Journal of Microbiology and Biotechnology, 22, 481-486.

Choma, IM and Grezelak, EM. (2010). Bioautography detection in thin-layer chromatography. Journal of Chromatography A, 1218(19), 2684-2691

Darah, I, Chong, CL, and Lim, SH. (2014). Antimicrobial activity of endophytic fungi isolated from Swietenia macrophylla leaves. Natural Product Communications, 9(2), 247-250

Ezhil, ASE., Kanagula, KA, Srigiridhar, K, Chandran, K, and Ayyappan, R. (2014). Cytotoxic and antibacterial activities of secondary metabolites from endophytic fungus Pestalotiopsis virgatula VN2. Current Research in Environmental \& Applied Mycology, 4(1), 107-115

Garcia, A, Rhoden, S, Bernardi-Wenzel, J, Orlandelli, RC, Azevedo, JL, and Pamphile, JA. (2012). Antimicrobial activity of crude extracts of endophytic fungi isolated from medicinal plant Sapindus saponaria L. Journal of Applied Pharmaceutical Science, 2(10), 35-40 
Grover, N and Patni, V. (2013). Phytochemical characterization using various solvent extracts and GC-MS analysis of methanolic extract of Woodfordia fructicosa (L.) Kurz. Leaves. International Journal of Pharmacy and Pharmaceutical Sciences, 5(4), 291-295

Hanson, LA, Zahn, EA, Wild, SR, Dopfer, D, Scott, J and Stein, C. (2012). Estimating global mortality from potentially foodborne diseases: an analysis using vital registration data. Population Health Matrices, 10(5), 1-7

Jorgensen, JH, and Ferraro, MJ. (2009). Antimicrobial susceptibility testing: a review of general principles and contemporary practices. Medical Microbiology, 49, 1749-55

Kuete, V. (2010). Potential of cameroonian plants and derived products against microbial infections: a review. Plant Medica, 76(14), 1479-1491

Kustrin, SA and Hettiarachchi, CG. (2014). Quantitative high performance thin layer chromatography for the analysis of herbal medicines: problems and advantages. Modern Chemistry and Applications, 2(1), 1-2

Moumita, D, Utpal, R, Runu, C, and Debasish, M. (2011). Role of diet and plants on diabetic patients. A critical appraisal. Science and Culture, $77,115-122$

Nagaraja, BK, Sripathy, R, Ramchand, CN and Sundararaman, M. (2011). Bioautography guided identification of anticandidal compounds from A. terreus st.1. American Journal of Infectious Diseases, 7(4), 91-97

Newell, D, Koopmans, M, Verhoef, L, Duizer, E, Aidara-Kane, A, Sprong, H, Opsteegh, M, Langelaar, M, Threfall, J, Scheutz, F, Giessen, J, and Kruse, H. (2010). Food-borne diseases- the challenges of 20 years ago still persist while new ones continue to emerge. International Journal of Food Microbiology, 139, 3-15

Pankey, GA and Sabath, LD. (2004). Clinica lrelevance of bacteriostatic versus bactericidal mechanism of actionin the treatment of Gram negative bacterial infections. Clinical Infectious Diseases, 38, 864-870

Petersen, JH, and Jensen, LK. (2010). Phthalates and food-contact materials: enforcing the 2008 European Union plastics legislation. Food Addictives and Contaminants: Part A, Chemistry, Analysis, Control, Exposure and Risk Assessment, 27(11), 1608-1616

Petrini, O, Sieber, T, Toti, L and Viret, O. (1992). Ecology metabolite production and substrate utilization in endophytic fungi. Natural Toxins, 1(3), 185-196

Petrus, AJA., Kalpana, K and Bharadha Devi, A. (2014). Antioxidant capacity and lipophilic constitution of Alternanthera bettzickiana flower extract. Oriental Journal of Chemistry, 30(2), 491-499

Porras-Alfaro A, Bayman P (2011). Hidden fungi, emergent properties: endophytes and microbiomes. Annual Review of Phytopathology, 49, 291-315.

Prasanna, P, Nandhini, B, Praveesh, BV, Angayarkanni, J and Palaniswamy, M. (2012). Novel angiotensin converting enzyme inhibitor from Aspergillus sp. by solid state fermentation. International Journal of Pharmacy and Pharmaceutical Sciences, 4(4), 371-377.

Ramasamy K, Lim SM, Bakar AB, Ismail N, Ismail MS, Ali MF, Weber JFF, Cole ALJ (2010). Antimicrobial and cytotoxic activities of Malaysian endophytes. Phytothear. Res, 24(5), 640-643.

Sadrati, N, Daoud, H, Zerroug, A, Dahanna, S and Bouharati, S. (2013). Screening of antimicrobial and antioxidant secondary metabolites from endophytic fungi isolated from wheat (Triticum durum). Journal of Plant Protection Research, 53(2), 128-136

Soheil, ZM, Goh, BH, Chan, CK, Tara, S. and Habsah, AK. (2013). Biological activities and phytochemicals of Swietenia macrophylla King. Molecules, 18(9), 10465-10483

Strobel GA. (2002). Rainforest endophytes and bioactive products. Critical Reviews in Biotechnology, 22(4), 315-333

Strobel, GA., Hess, WM., Ford E., Sidhu RS, Yang X. (1996). Taxol from fungal endophyte and issue of biodiversity. Journal of Industrial Microbiology, 17, 417-423

Suleimana, MM, McGaw, LJ, Naidoo, V, and Eloff, JN. (2010). Detection of antimicrobial compounds by bioautography of different extracts of leaves of selected South African tree species. African Journal of Traditional, Complementary and Alternative Medicine, 7(1), 64-78

Tambekar, DH, Tiwari, AA and Tambekar, SD. (2014). Studies on production of antimicrobial substances from Bacillus species isolated from Lonar Lake. Indian Journal of Applied Research, 4(8), 502-506

Tan, SK, Hasnah, O, Wong, KC, Boey, PL, and Padzilah, I. (2009). Antimicrobial and antioxidant activities of Swietenia macrophylla leaf extracts. Asian Journal of Food and Agro-Industry, 2(2), 181-188

Tong, WY, Chong, CL, Darah, I and Latifah, Z. (2012). Enhancement of anti-candidal activity of endophytic fungus Phomopsis sp. ED2, isolated from Orthosiphon stamineus Benth, by incorporation of host plant extract to culture medium. The Journal of Microbiology, 50(4), 581-585

Tong, WY, Darah, I and Latifah, Z. (2011). Antimicrobial activities of endophytic fungal isolates from medicinal herb Orthosiphon stamineus Benth. Journal of Medicinal Plant Research, 5(5), 831-836

Tong, WY, Syarifah, AR, Nurhaida, Latiffah, Z and Darah, I. (2014). In vivo anti-MRSA activity of Penicillium minioluteum ED24. Journal of Applied Pharmacy, 6(2), 184-194

Toronto Research Chemicals. (2014). Di-n-octyl phthalate. [Online]. [Accessed 24 ${ }^{\text {th }}$ November 2014]. Available from World Wide Web: http:/ / www.trc-canada.com/detail.php?CatNum=D481750

Vimalavady, A and Kadavul, K. (2013). Phytocomponents identified on the various extracts of stem of Hugonia mystax L. (Linaceae). European Journal of Experimental Biology, 3(1), 73-80

Wang, FW, Jiao, RH, Cheng, AB, Tan, SH And Song, YC. (2007). Antimicrobial potentials of endophytic fungi residing in Quercus variabilis and brefeldin A obtained from Cladosporium sp. World Journal of Microbiology and Biotechnology, 23, 79-83

$$
--0 \text {-- }
$$

